\title{
Gear fault detection using artificial neural networks with discrete wavelet transform and principal component analysis
}

\author{
M. Er-raoudi ${ }^{1}$, M. Diany ${ }^{1}$, H. Aissaoui ${ }^{2}$ and M. Mabrouki ${ }^{1}$ \\ ${ }^{1}$ Industrial Engineering Laboratory, Faculty of science and technology \\ Beni Mellal, Morocco \\ ${ }^{1}$ Email:erraoudi.mina@gmail.com \\ ${ }^{2}$ Sustainable development Laboratory, Faculty of science and technology \\ Beni Mellal, Morocco
}

\begin{abstract}
The current work aims to develop a classification method devoted to gear defect diagnosis. In this paper, the proposed classification method is based on the Neural Networks, Discrete Wavelet Transform and Principal Component Analysis. A gearbox system with six degrees of freedom (DOF) is simulated in MATLAB and Simulink. Defects are introduced in the model by the meshing stiffness function which is computed by considering in series the bending, shear, axial compressive, fillet foundation and Hertzian stiffness. The signals dataset is collected by changing system or defect parameters. In addition, an experimental data is tested with the proposed method. Signal features are extracted using the Discrete Wavelet Transform with the Principal Component Analysis. This method allows us to classify the extracted features into two classes, healthy and faulty, with a good rate of correct classification. Both simulated and experimental data are tested with the proposed method.
\end{abstract}

Keywords: Monitoring; Fault; Gears; classification; Neural Networks.

\section{INTRODUCTION}

Gears are very widespread equipment in mechanic and in the majority of the industrial fields. They are used to transmit motion and power between two shafts with a constant speed ratio. Unfortunately, gears are subjected to defects during their operating time hence the necessity of the diagnosis and monitoring in order to increase reliability and reduce production losses caused by a failure of the machine components. The early diagnosis of the gear defects, based on vibration analysis, recently arouses more interest in the world of scientific research [1-6]. The present work belongs to learning category as application in gear and gearbox defects detection based on Artificial Neural Network, incorporating Discrete Wavelet Transform and Principal component Analysis. Nowadays much attention has been paid to this field, and many studies are conducted to detect defects by artificial intelligence tools [7-10]. Samanta [7] presented a comparative study of two classifiers; artificial neural networks and support vector machine, with genetic algorithm based features selection from time-domain vibration signals. Wuxing et al [8] proposed an effective method for classifying machine faults that exhibit non-linear and noisy signals using the cumulants and the radial basis function network. Lei et al [9] classified the different levels of gear cracks automatically and reliably based on weighted K-nearest neighbour algorithm. Saravanan et al [10] used the fuzzy logic technique to identify defects of the spur bevel gearbox. An artificial neural networks (ANN) based 
fault detection system to increase reliability is developed in reference [6] where two prominent fault conditions in gears, worn-out and broken teeth are studied. ZhiQiang Chen et al. [11] proposed a deep learning technique based algorithm convolutional neural network $(\mathrm{CNN})$ for the vibration measurements to diagnose the fault patterns of the gearbox.

In the above works, the data is collected by experimentation while in this paper it is by simulation. The main objective of this work is to propose an intelligent method based on gear tooth crack detection and to simulate a six DOF gearbox system. The study of the gears and gearbox system is based on the mesh stiffness function. The presence of defects causes more vibration and noise and a drop in the meshing stiffness [12, 13]. Many research studies were conducted to calculate the gear mesh stiffness and to model defects to evaluate their effects on the Time Varying Mesh Stiffness [14-17].Thus, several models of gear system were developed [18, 19]. The Time Varying Mesh stiffness computation is performed using the potential energy method, taking into account the effects of bending, compression, shear, elastic foundation and Hertz [20, 21]. By changing the gear tooth parameters, the signal data is collected. The proposed system based on Artificial Neural Networks, Discrete Wavelet Transform with Principal Component Analysis is also used with an experimental data. It is shown that both simulated and experimental signals can be used with this method.

\section{METHODS AND MATERIALS}

\section{Wavelet Transform}

The principle of Wavelet Transform is to decompose signal into wavelets with different scales and positions [22, 23]. These wavelets are obtained by expanding or contracting the mother wavelet and by translating it along the time axis. We have distinguished two types of wavelet transform: continuous and discrete.

The Continuous Wavelet Transform (CWT) of a signal $x(t)$ is as follows [22]:

$$
W(a, b)=\frac{1}{\sqrt{a}} \int_{-\infty}^{+\infty} x(t) \psi^{*}\left(\frac{t-b}{a}\right) d t
$$

where $\psi(\mathrm{t})$ is the mother wavelet, $\psi^{*}(\mathrm{t})$ is the complex conjugate of $\psi(\mathrm{t})$, a and $\mathrm{b}$ are the dilation and translation parameters respectively, $a \in R+-[1], b \in R$.

The Discrete Wavelet Transform (DWT), instead of CWT, is implanted using the Mallat algorithm using the multi-resolution analysis [24]. It is used to introduce the analyzed signal in two filters; low-pass (h) and high-pass (g). At this level, two vectors are obtained, and they are $A_{1}$ and $D_{1}$. Elements of vector $A_{1}$ are called approximation coefficients while the elements of vector $\mathrm{D}_{1}$ are called detail coefficients. This procedure can be repeated with the elements of vector $A_{1}$ and successively with each new obtained vector $A_{K}$. During the process of this decomposition the signal $x(t)$ and the vectors $A_{K}$ undergo undersampling. The signal $x(t)$ reconstruction is by introducing $A_{K}$ and $D_{k}$ into two filters $\bar{h}$ and $\bar{g}$ respectively, which are the conjugates of $h$ and $g$ respectively, preceded by an on sampling. The process of this decomposition and reconstruction is shown in Figure1.

\section{Principal component Analysis}

The Principal Component Analysis (PCA) is a linear transformation, which is essentially to project the data on their covariance eigenvectors basis. The correlated variables are replaced by new variables, uncorrelated with maximum variance, established by linear 
combinations of the original variables [25]. The PCA aims to reduce data in a minimum of components by projecting it in a multidimensional space to a subspace [26]. Indeed, the minimization of the information losses due to projection by maximizing the projected variance is essential. The matrix of eigenvectors used by the PCA is orthogonal and therefore reversible by simple transposition. This characteristic of the PCA allows the reconstruction of the signal.
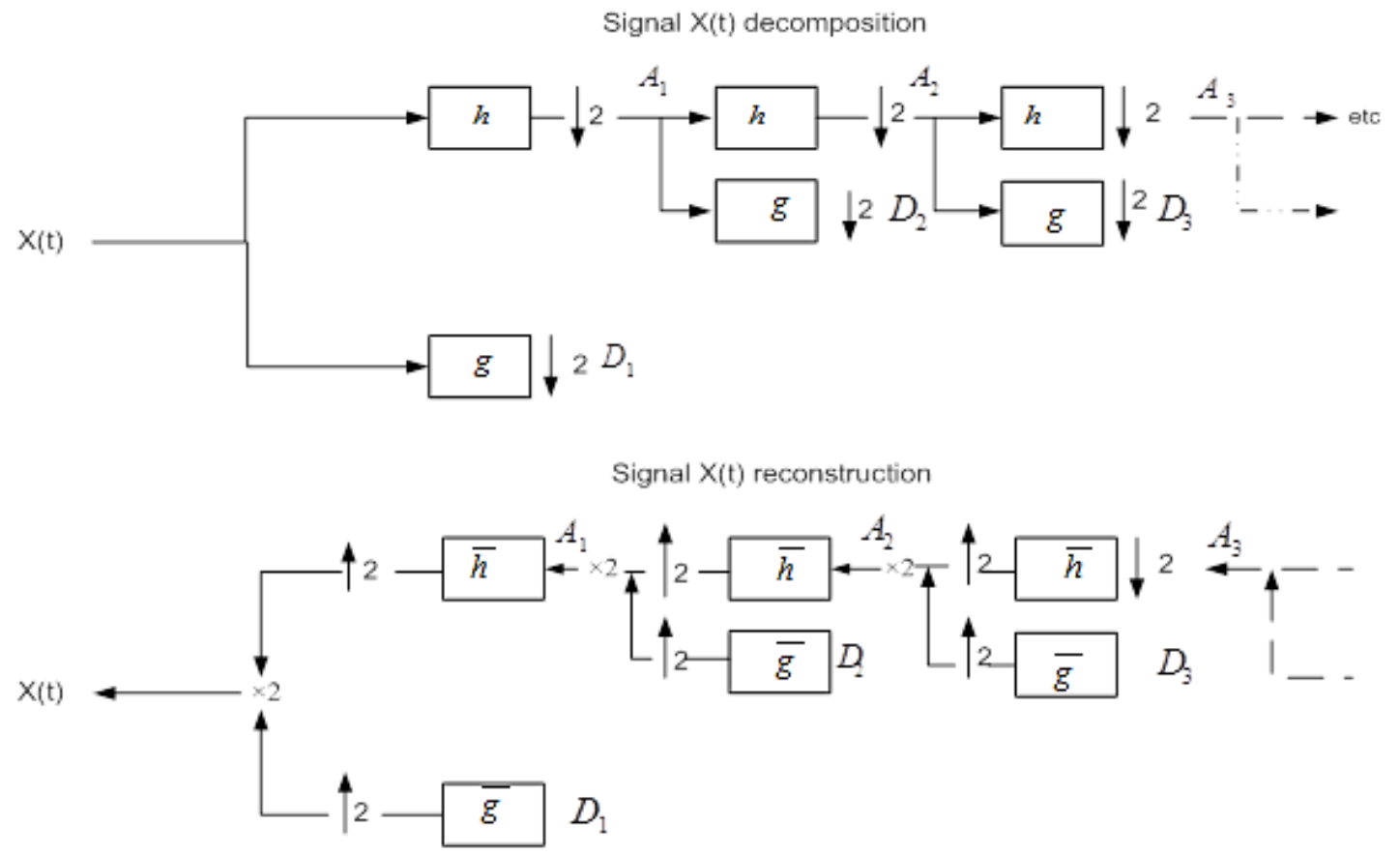

Figure 1. Process of a signal decomposition and reconstruction by the DWT.

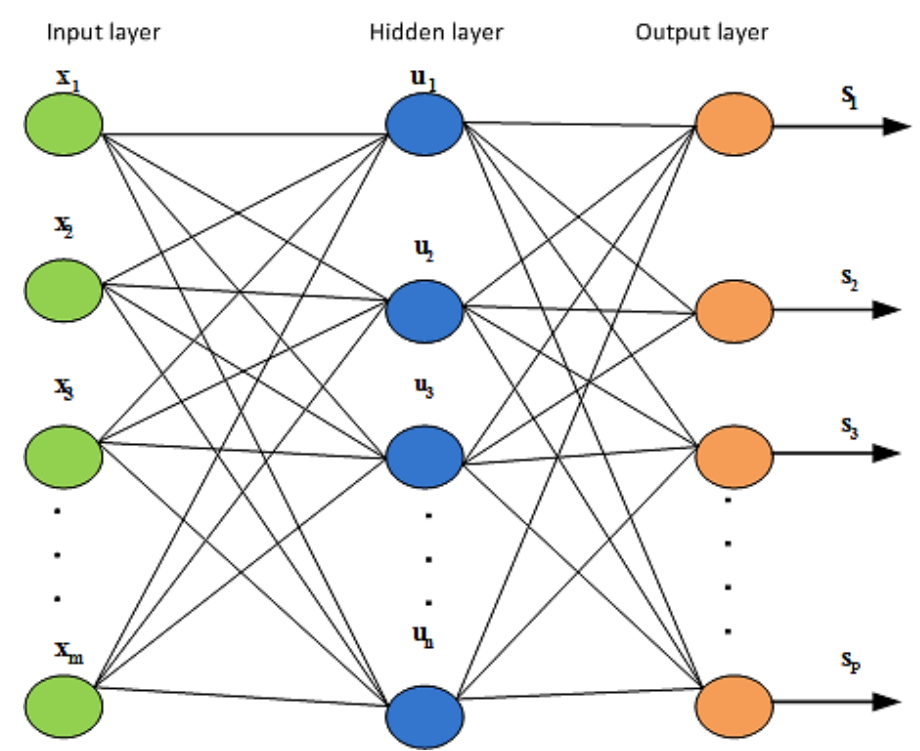

where $\mathrm{x}_{\mathrm{m}}$ is the input vector, $\mathrm{u}_{\mathrm{n}}$ is the hidden layer neurone, $\mathrm{s}_{\mathrm{p}}$ is the output vector

Figure 2. Structure of the multilayer perceptron. 


\section{Artificial Neural Networks}

Artificial Neural Networks (ANNs) are intelligent systems inspired from biological neural networks and composed from simple elements operating in parallel way. The basic neural network is the perceptron that is used to find solution for linear problems [27]. In order to solve non-linear problems, an intermediate layer between the input and the output of the monolayer perceptron is added. This added layer is called 'hidden layer' and the resulting network is called 'multilayer' perceptron (MLP) [28]. The MLP consists of an input layer of source nodes, one or more hidden layers of computation nodes called neurons and an output layer as illustrated in Figure 2. The number of nodes in the input and the output layers depends on the number of input and output variables respectively. The number of hidden layers and the number of nodes in each hidden layer affects the generalization capability of the network. The training of an MLP network involves finding values of the connection weights, which minimize an error function between the actual network output and the corresponding target values in the training set. One of the widely used error functions is mean square error (MSE) and the most commonly used training algorithm is back-propagation [29].

\section{MATHEMATICAL MODELLING}

\section{Mechanical Model}

The gear model used in this study is developed by Bartelmus [18] which is presented in Figure 3. It has six DOFs with time varying mesh stiffness. The equations of motion are as follows [18]:

$$
\left\{\begin{array}{l}
m_{p} \ddot{x}_{p}=-k_{x p} x_{p}-c_{p} \dot{x}_{p} \\
m_{g} \ddot{x}_{g}=-k_{x g} x_{g}-c_{g} \dot{x}_{g} \\
m_{p} \ddot{y}_{p}=-k_{1} y_{p}-c_{1} \dot{y}_{p}+K_{t}\left(R_{b p} \theta_{p}-R_{b g} \theta_{g}-y_{p}+y_{g}\right)+C\left(R_{b p} \dot{\theta}_{p}-R_{b g} \dot{\theta}_{g}-\dot{y}_{p}+\dot{y}_{g}\right) \\
m_{g} \ddot{y}_{g}=-k_{2} y_{g}-c_{2} \dot{y}_{g}+K_{t}\left(R_{b p} \theta_{p}-R_{b g} \theta_{g}-y_{p}+y_{g}\right)+C\left(R_{b p} \dot{\theta}_{p}-R_{b g} \dot{\theta}_{g}-\dot{y}_{p}+\dot{y}_{g}\right) \\
I_{p} \ddot{\theta}_{p}=k_{p}\left(\theta_{m}-\theta_{p}\right)+c_{p}\left(\dot{\theta}_{m}-\dot{\theta}_{p}\right)-R_{b 1}\left(\mathrm{~K}_{t}\left(R_{b p} \theta_{p}-R_{b g} \theta_{g}-y_{p}+y_{g}\right)+C\left(R_{b p} \dot{\theta}_{p}-R_{b g} \dot{\theta}_{g}-\dot{y}_{p}+\dot{y}_{g}\right)\right) \\
I_{g} \ddot{\theta}_{g}=k_{g}\left(\theta_{g}-\theta_{l}\right)+c_{g}\left(\dot{\theta}_{g}-\dot{\theta}_{l}\right)-R_{b 1}\left(K_{t}\left(R_{b p} \theta_{p}-R_{b g} \theta_{g}-y_{p}+y_{g}\right)+C\left(R_{b p} \dot{\theta}_{p}-R_{b g} \dot{\theta}_{g}-\dot{y}_{p}+\dot{y}_{g}\right)\right) \\
I_{m} \ddot{\theta}_{m}=M_{1}-k_{p}\left(\theta_{m}-\theta_{p}\right)-c_{p}\left(\dot{\theta}_{m}-\dot{\theta}_{p}\right) \\
I_{l} \ddot{\theta}_{l}=-M_{2}+k_{g}\left(\theta_{g}-\theta_{l}\right)+c_{g}\left(\dot{\theta}_{g}-\dot{\theta}_{l}\right)
\end{array}\right.
$$

where:

$\mathrm{R}_{\mathrm{p}} / \mathrm{R}_{\mathrm{g}}$ is the base circle radius of pinion/gear, $\mathrm{m}_{\mathrm{p}} / \mathrm{m}_{\mathrm{g}}$ is the mass of pinion/gear, $I_{M} / I_{L}$ is the mass moment of inertia of the motor/load, $I_{g} / I_{g}$ is the masse moment of inertia of the pinion/gear, $M_{1}$ is the input motor torque, $M_{2}$ is the output torque from load, $M_{p k} /$ $M_{g k}$ is the, stiffness moment of input/output coupling, $M_{p c} / M_{g c}$ is the damping moment of input/output coupling, $\mathrm{k}_{1} / \mathrm{k}_{2}$ is the vertical radial stiffness of the input/output bearings, $\mathrm{k}_{\mathrm{xp}} / \mathrm{k}_{\mathrm{xg}}$ is the horizontal stiffness of the input/output bearings, $\mathrm{c}_{\mathrm{xp}} / \mathrm{c}_{\mathrm{xg}}$ is the horizontal damping coefficient of the input/output bearings, $\mathrm{c}_{\mathrm{p}} / \mathrm{c}_{\mathrm{g}}$ is the damping coefficient of the input/output flexible coupling, $\mathrm{k}_{\mathrm{p}} / \mathrm{kg}_{\mathrm{g}}$ is the torsional stiffness of the input/output flexible coupling, $\mathrm{x}_{\mathrm{p}} / \mathrm{x}_{\mathrm{g}}$ is the linear displacement of the pinion/gear in the $\mathrm{x}$ direction, $\mathrm{y}_{\mathrm{p}} / \mathrm{y}_{\mathrm{g}}$ is the linear displacement of the pinion/gear in the y direction. 


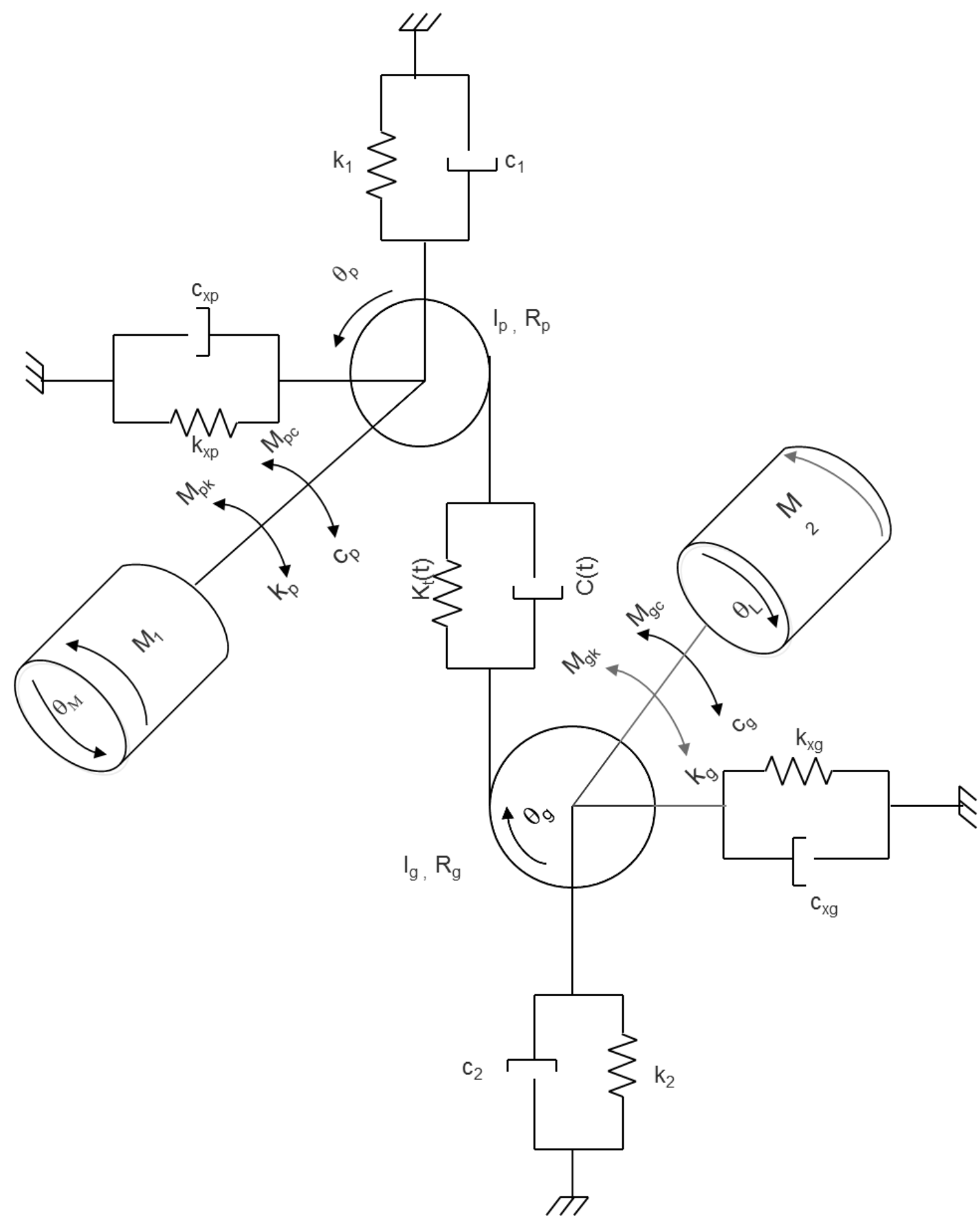

Figure 3. Six DOF gearbox system [18].

\section{Time Varying Mesh Stiffness}

The Time Varying Mesh Stiffness (TVMS), Kt, is computed based on the potential energy method [20]. The tooth is considered as a cantilevered beam at the base circle [12] as represented in Figure 4. The TVMS is obtained by calculating the stiffness of bending, compression, shear, elastic foundation and Hertz contact, respectively, $\mathrm{k}_{\mathrm{b}}, \mathrm{k}_{\mathrm{a}}, \mathrm{k}_{\mathrm{s}}, \mathrm{k}_{\mathrm{f}}$ and $\mathrm{k}_{\mathrm{h}}$ [16]. For a contact force $\mathrm{F}$, the bending, hertzian, shear, axial compressive and fillet foundation energy are, respectively defined by:

$$
\mathrm{U}_{\mathrm{b}}=\frac{\mathrm{F}^{2}}{2 \mathrm{k}_{\mathrm{b}}}, \mathrm{U}_{\mathrm{h}}=\frac{\mathrm{F}^{2}}{2 \mathrm{k}_{\mathrm{h}}}, \mathrm{U}_{\mathrm{s}}=\frac{\mathrm{F}^{2}}{2 \mathrm{k}_{\mathrm{s}}}, \mathrm{U}_{\mathrm{a}}=\frac{\mathrm{F}^{2}}{2 \mathrm{k}_{\mathrm{a}}}
$$


where $\mathrm{U}_{\mathrm{b}}=\int_{0}^{\mathrm{L}} \frac{\mathrm{M}_{\mathrm{y}}{ }^{2}}{2 \mathrm{I}_{\mathrm{y}}}, \mathrm{U}_{\mathrm{s}}=\int_{0}^{\mathrm{L}} \frac{1.2 \mathrm{~F}_{\mathrm{r}}^{2}}{2 \mathrm{I}_{\mathrm{y}}}, \mathrm{U}_{\mathrm{a}}=\int_{0}^{\mathrm{L}} \frac{\mathrm{F}_{\mathrm{a}}{ }^{2}}{2 \mathrm{EA}_{\mathrm{y}}}$

With $G=\frac{E}{2(1+\vartheta)}, I_{y}=(2 x)^{3} \mathrm{~L} / 12, A_{y}=2 \times L$

The fillet foundation deflection is calculated using ref [21] formula:

$$
\delta_{\mathrm{f}}=\frac{\mathrm{F} \cos ^{2} \alpha_{\mathrm{m}}}{\mathrm{LE}}\left\{\mathrm{L} *\left(\frac{\mathrm{u}_{\mathrm{f}}}{\mathrm{s}_{\mathrm{f}}}\right)^{2}+\mathrm{M} *\left(\frac{\mathrm{u}_{\mathrm{f}}}{\mathrm{s}_{\mathrm{f}}}\right)+\mathrm{P} *\left(1+\mathrm{Q} * \tan ^{2} \alpha_{\mathrm{m}}\right)\right\}
$$

The coefficients $\mathrm{u}_{\mathrm{f}}, \mathrm{s}_{\mathrm{f}}, \mathrm{P}$ and $\mathrm{Q}$ can be found in [21] and Figure 4 represents the geometrical parameters for the fillet - foundation deflection.

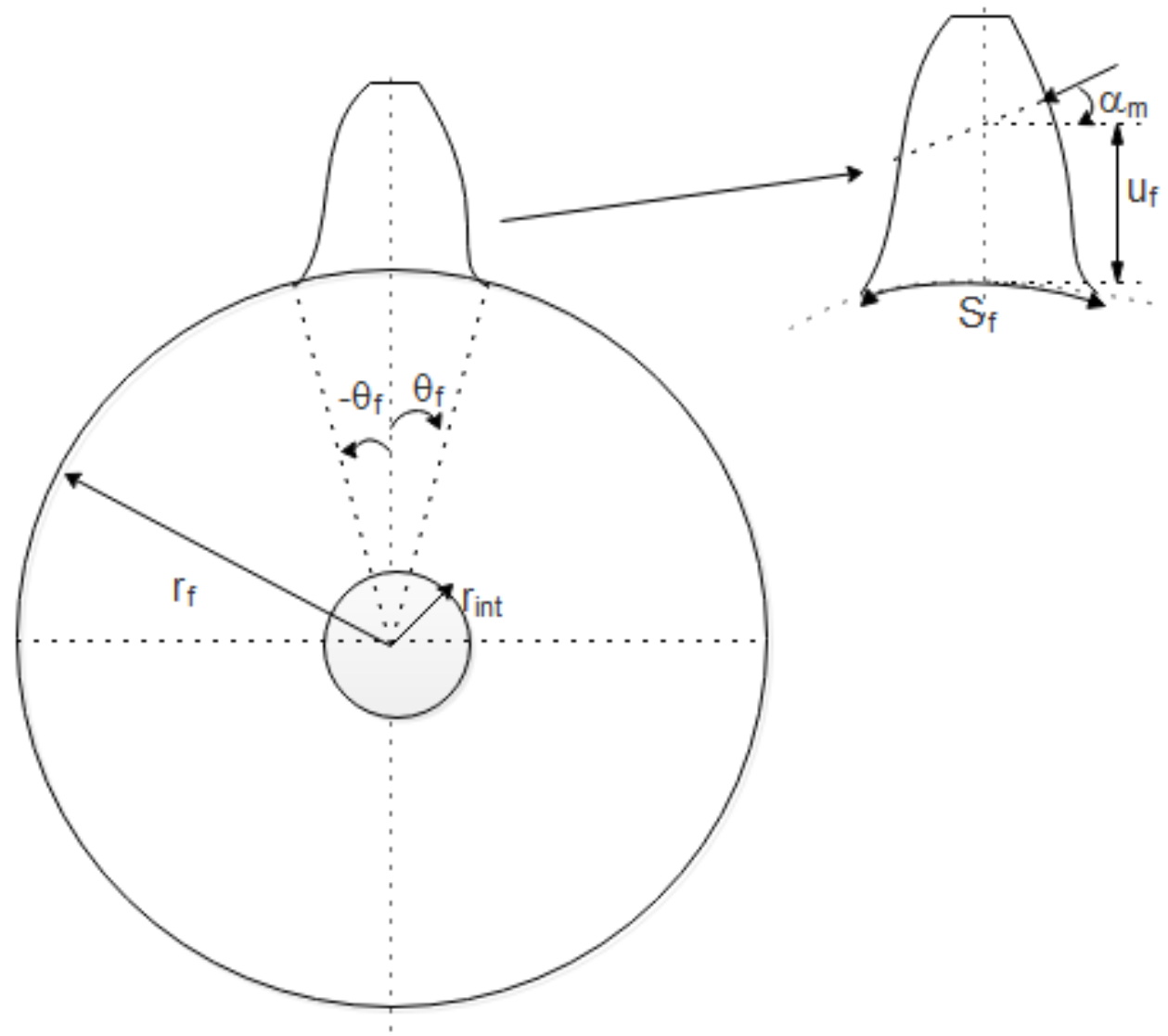

Figure 4. Geometrical parameters for the fillet-foundation deflection [14].

The total mesh stiffness is:

$$
\mathrm{K}_{\mathrm{t}, \mathrm{i}}=\sum_{\mathrm{i}=1}^{2} \frac{1}{\frac{1}{\mathrm{k}_{\mathrm{h}}}+\frac{1}{\mathrm{k}_{\mathrm{b} 1, \mathrm{i}}}+\frac{1}{\mathrm{k}_{\mathrm{s} 1, \mathrm{i}}}+\frac{1}{\mathrm{k}_{\mathrm{a} 1, \mathrm{i}}}+\frac{1}{\mathrm{k}_{\mathrm{f} 1, \mathrm{i}}}+\frac{1}{\mathrm{k}_{\mathrm{b} 2, \mathrm{i}}}+\frac{1}{\mathrm{k}_{\mathrm{s} 2, \mathrm{i}}}+\frac{1}{\mathrm{k}_{\mathrm{a} 2, \mathrm{i}}}+\frac{1}{\mathrm{k}_{\mathrm{f} 2, \mathrm{i}}}}
$$

where $\mathrm{i}$ is the number of teeth pair in contact.

In the presence of crack, the tooth is still considered as a cantilevered beam [12]. The crack is defined by its inclination angle $\Theta$ and depth $\mathrm{q}_{1}$ as represented in Figure 5. 


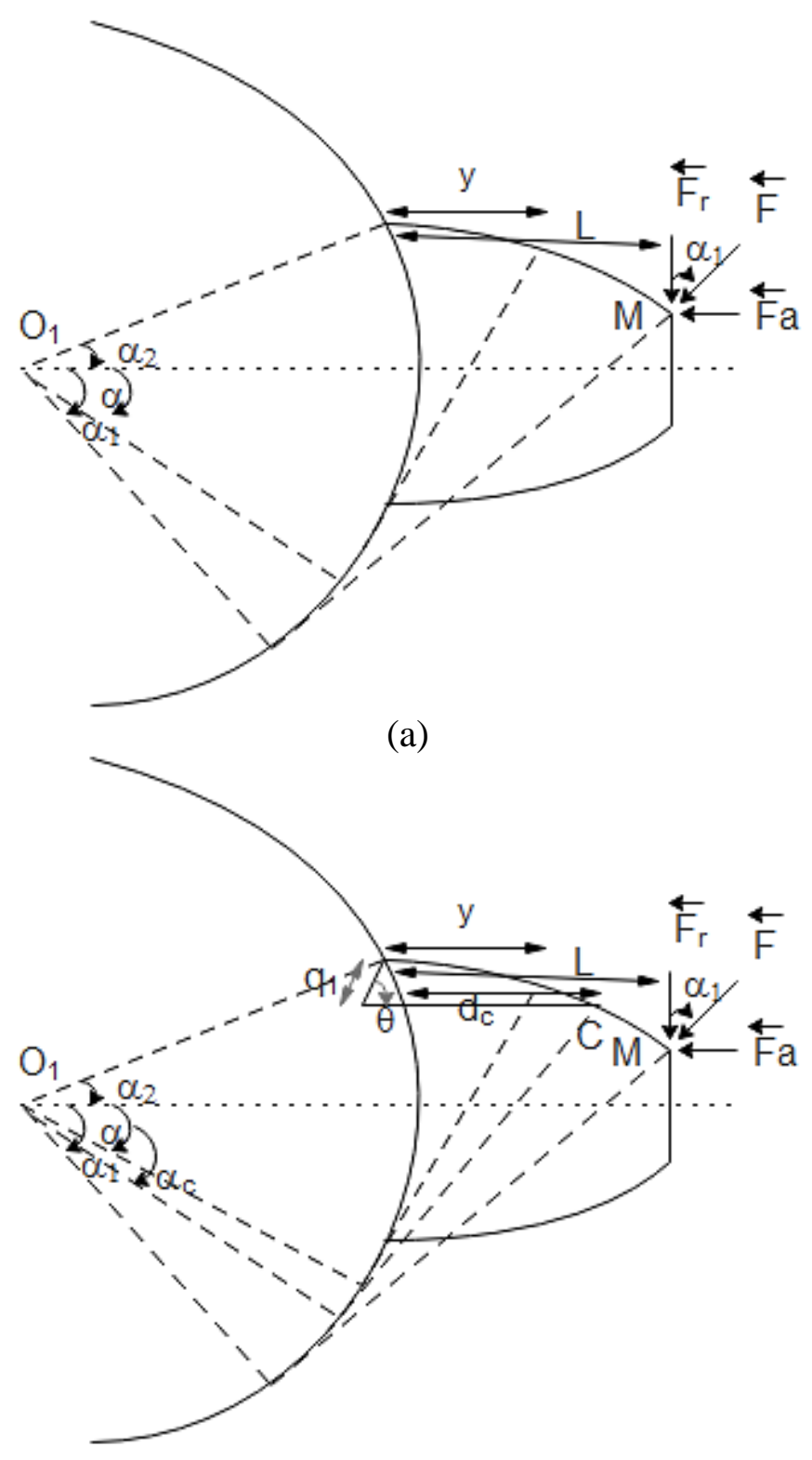

(b)

where $\alpha_{2}$ is the half tooth angle on the base circle, $M$ is the contact point and $d_{c}$ is the crack length.

Figure 5. Gear tooth modelling [12] (a) for healthy case; (b) for cracked case

\section{RESULTS AND DISCUSSION}

The detailed steps of the proposed method are as follows:

\section{Features Extraction}

The first step in the pattern recognition approach is the features extraction, which is the transformation of patterns into features considered as a compacted representation. There are several methods for feature extraction in time domain, frequency, time-frequency and statistical approaches. In this work, features are extracted using DWT since it can extract more information from signal. 


\section{Features Selection}

Before giving the extracted features to the ANNs, we must select the features that represent more information. The method used here is the Principal Component Analysis.

\section{Classification}

In order to classify our data into classes; healthy and defected ones, the network used is the MLP. The sigmoid function is used as activation function in the hidden and in the output layers. The ANNs are created, trained and implemented using MATLAB neural network toolbox with back-propagation neural network (BPN). The ANNs are trained iteratively to minimize the performance function of mean square error (MSE) between the network outputs and the corresponding target values. At each iteration, the gradient of the performance function (MSE) is used to adjust the network weights and biases.

\section{Simulated Data}

In this work, the numerical simulation of the mechanical system represented in Figure 3 is made with the parameters of the pinion wheel set given in Table 1. The TVMS obtained is periodic and takes slots form. The presence of crack causes fall in the TVMS value as illustrated in Figure 6. The value of shock in the TVMS depends on the fault severity.

Table 1. Parameters of the pinion wheel set [14].

\begin{tabular}{|c|c|c|}
\hline & pinion & Wheel \\
\hline Teeth number & $Z_{1}=25$ & $Z_{2}=30$ \\
\hline Module(mm) & 2 & 2 \\
\hline Teeth width(mm) & 20 & 20 \\
\hline Contact ratio & 1.63 & 1.63 \\
\hline Rotational speed(Rpm) & 2400 & 2000 \\
\hline Pressure angle & $20^{\circ}$ & $20^{\circ}$ \\
\hline Young modulus E(N/mm²) & $2.10^{5}$ & $2.10^{5}$ \\
\hline Poisson ratio & 0.3 & 0.3 \\
\hline
\end{tabular}

The obtained signal $y_{p}$, representing the displacement of the pinion in the $y$ direction, is shown in Figure 7. Figure 7 (a) indicates the presence of periodic shocks, equal to the pinion rotation period $(0.025 \mathrm{~s})$ which contains the cracked tooth, in the signal as shown in Figure 7(a). The used vibratory signal dataset is obtained by changing the gear and crack parameters. The signal dataset consists of 40 signals which are divided into two databases; one for training and the other for the test. The two datasets are composed of 20 signals in the presence and absence of the defect. These signals are obtained by changing the depth, the crack inclination angle, the position and the thickness of the crack as illustrated in Figure 6. Figure 8 shows an example of signals in training data.The mother wavelet and the level decomposition are selected to have a good recognition rate. The mother wavelet used is Daubechies 'db5' at level 4. Figure 9 gives an example of signal decomposition by DWT. By the PCA each vector size of features is reduced into 18 features which are classified using the ANNs. The best value obtained for the MSE is equal to 8.58.10-7 with 29 iterations. The rate of correct classification is $95 \%$, which shows that the proposed method is a powerful classification tool and justifies the choice of the DWT and the PCA for signal features extraction and selection. 
Gear fault detection using artificial neural networks with discrete wavelet transform and principal component analysis

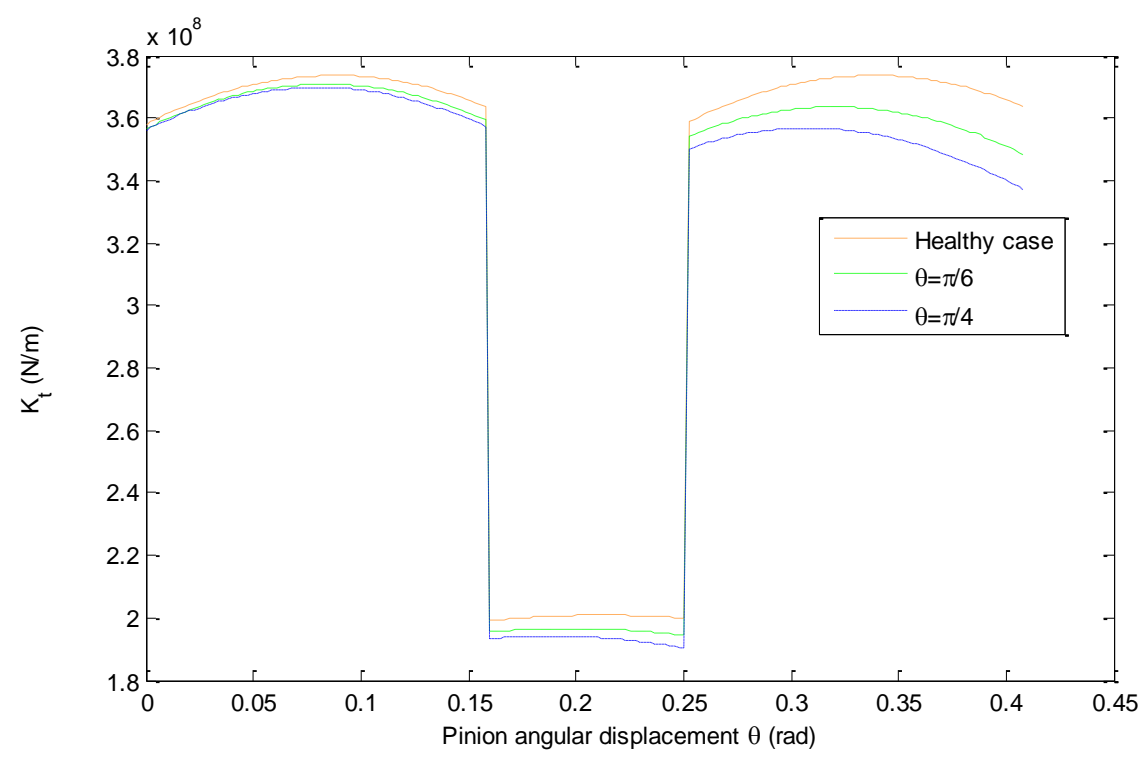

(a)

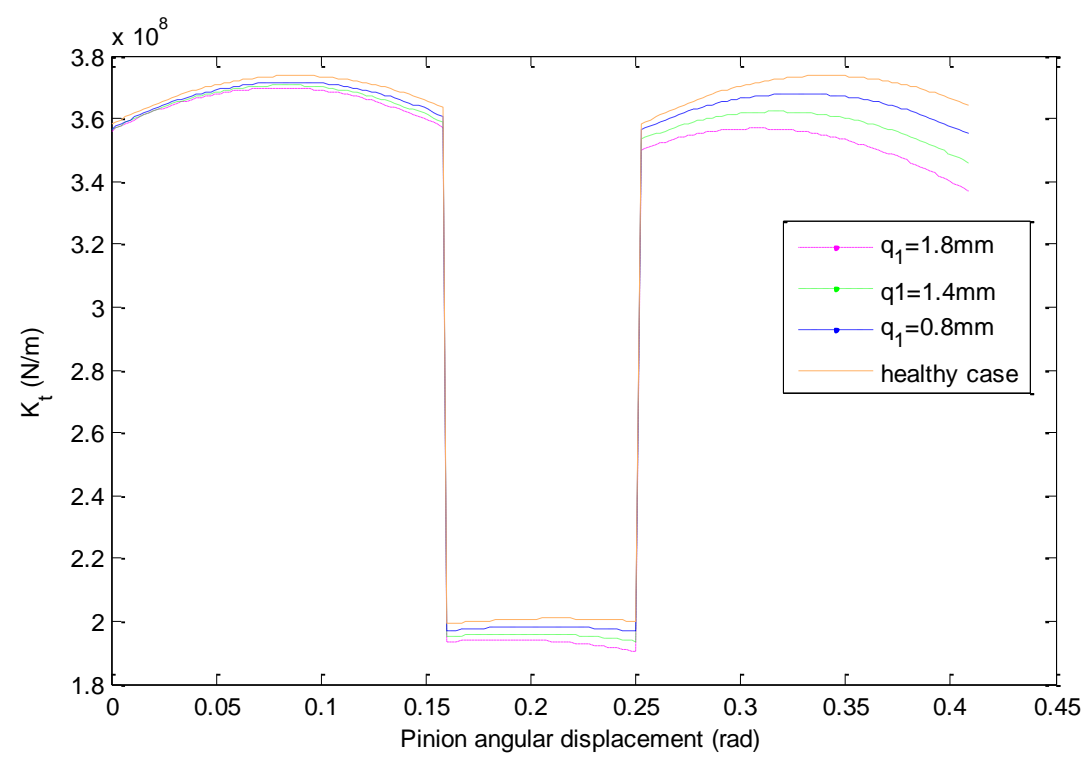

(b)

Figure 6. TVMS versus the pinion angular displacement (a) $\mathrm{q}_{1}=1.8 \mathrm{~mm}$; (b) $\Theta=\pi / 4$.
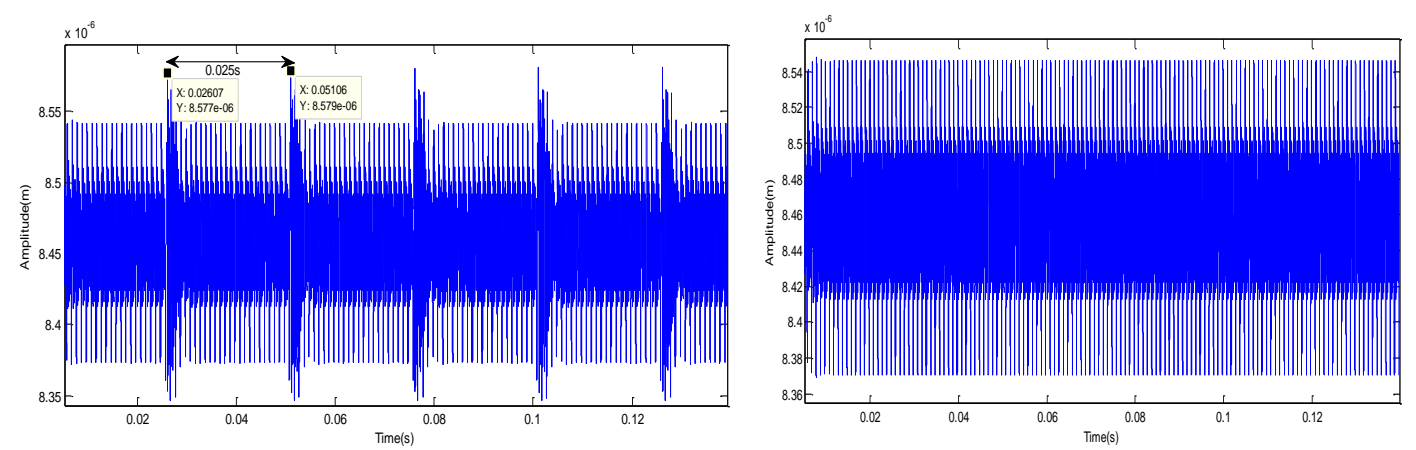

Figure 7. Pinion displacement signal (a) for the cracked case, (b) for the healthy case. 

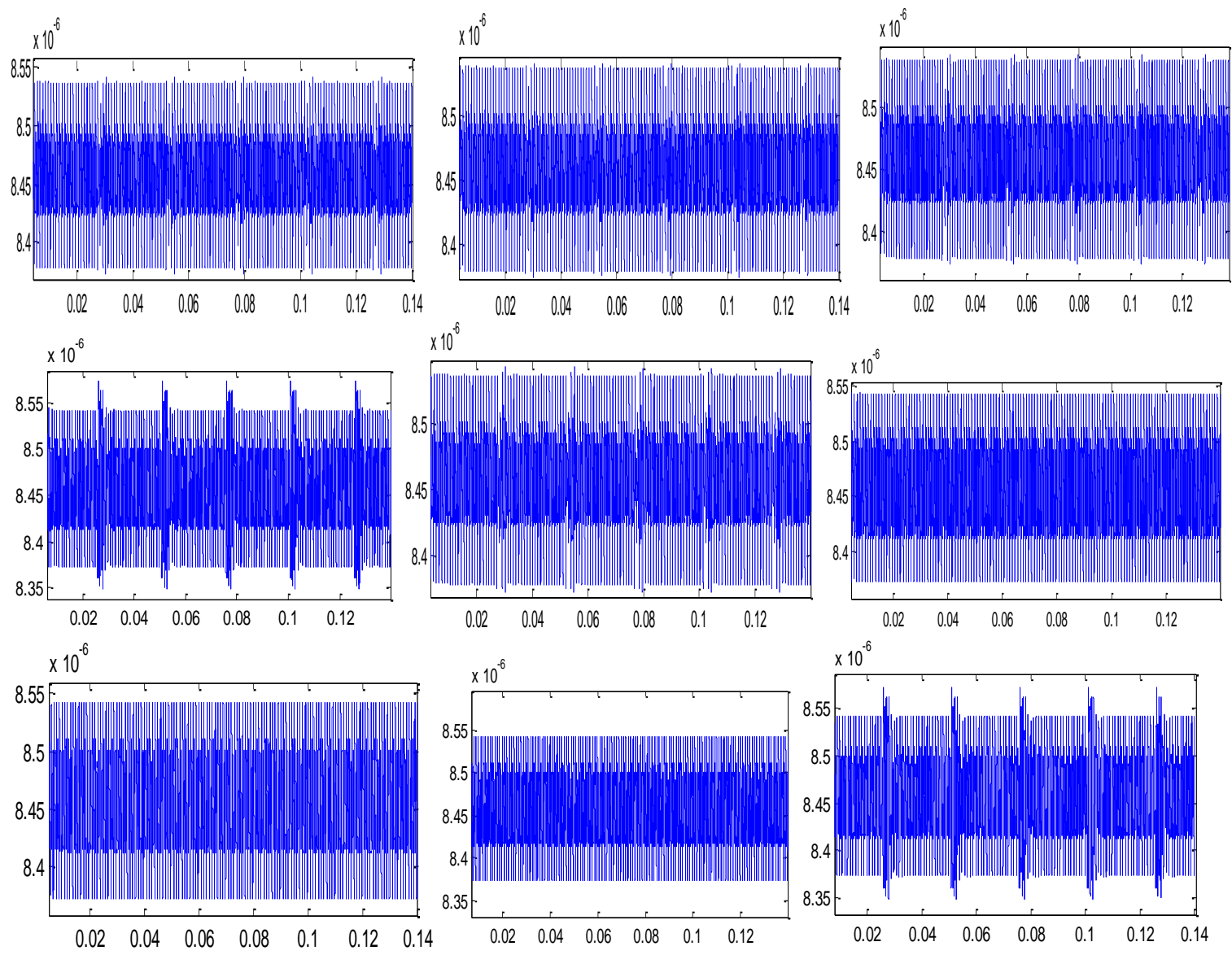

Figure 8. Signals from the training dataset.

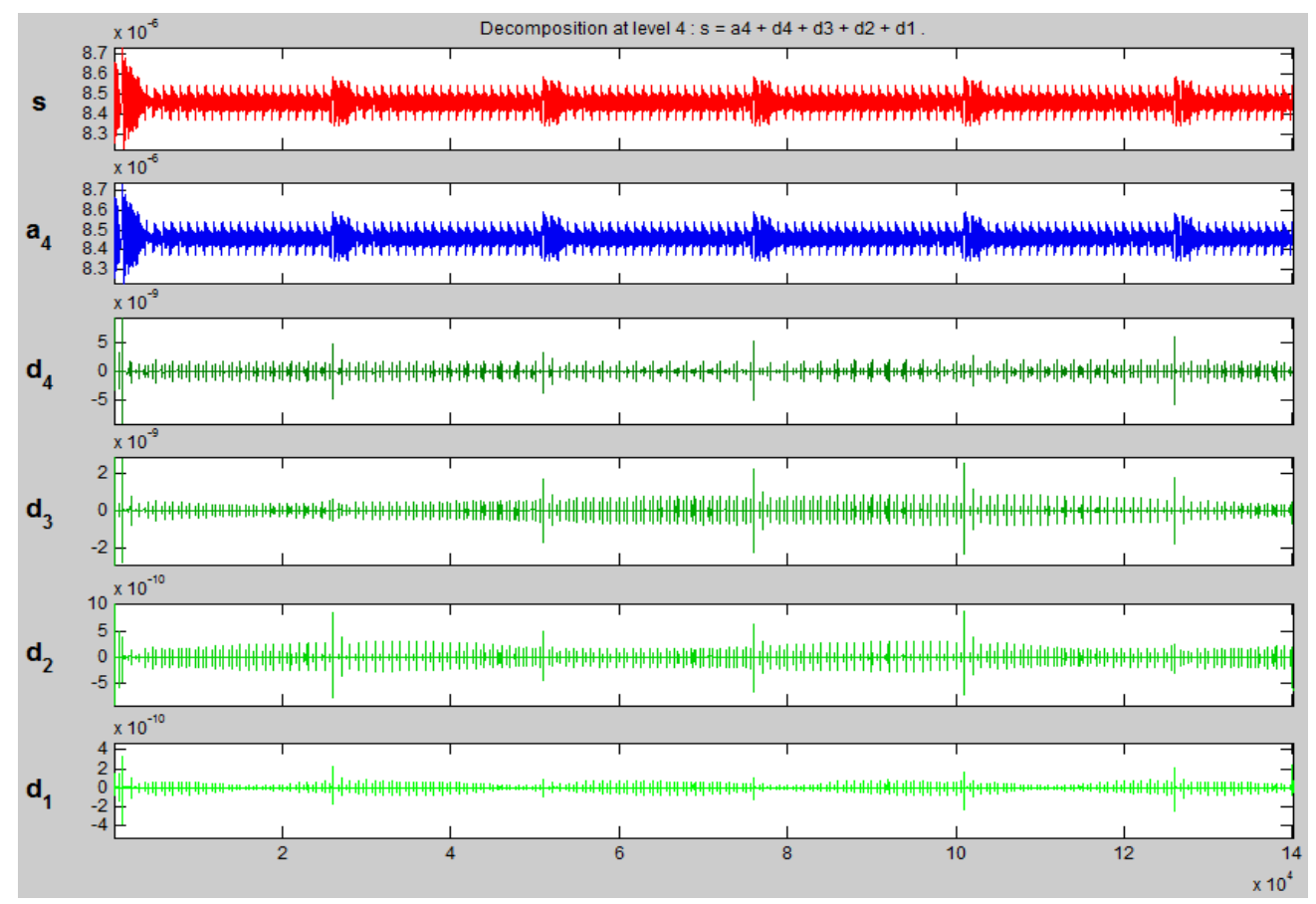

Figure 9. Example of DWT signal decomposition. 


\section{Experimental data}

In reality, simulated and experimental signals are somewhat different as a simulated signal represents the ideal case. Indeed, the fact is, an experimental signal may contain noise as well as it may have other components dependent on the operating conditions of the machine. The objective of this part is to test the proposed method with an experimental data. The vibratory signal data used in this part comes from the tests carried out on the CETIM gearbox test bench, running 24h/24h, the based gears are with the ratio 20/21 [30, 31] .The dimensioning of the tempered hardened gear wheels and the operating conditions (speed, torques) are fixed to obtain a peeling over the entire tooth length. The test is during 12 days then every day after the acquirement of the vibratory signal, the bench is stopped in order to observe the status of the tooth wheels. The speed of the drive motor is 1000 $\operatorname{rpm}(16.67 \mathrm{~Hz})$ therefore the rotational speed of the wheel is $952.38 \mathrm{rpm}(15.87 \mathrm{~Hz})$ and the meshing frequency is $333.33 \mathrm{~Hz}$. The sampling frequency is $20 \mathrm{Khz}$ and the size of each signal is 60000 in the duration of 3 seconds.

Table 2. Signals data test by the artificial neural networks.

\begin{tabular}{|c|c|c|c|}
\hline Signal day & Vector test & Obtained class & Desired class \\
\hline \multirow[t]{2}{*}{2} & $9.897377862129140 \mathrm{e}-01$ & 1 & 1 \\
\hline & $1.132151810515625 \mathrm{e}-04$ & & \\
\hline \multirow[t]{2}{*}{3} & $9.897377862129140 \mathrm{e}-01$ & 1 & 1 \\
\hline & $1.132151810515625 \mathrm{e}-04$ & & \\
\hline \multirow[t]{2}{*}{4} & $1.632938603652878 \mathrm{e}-04$ & 2 & 1 \\
\hline & $9.770642951535482 \mathrm{e}-01$ & & \\
\hline \multirow[t]{2}{*}{5} & $9.897377862129140 \mathrm{e}-01$ & 1 & 1 \\
\hline & $1.132151810515625 \mathrm{e}-04$ & & \\
\hline \multirow[t]{2}{*}{6} & $9.897377862129140 \mathrm{e}-01$ & 1 & 1 \\
\hline & $1.132151810515625 \mathrm{e}-04$ & & \\
\hline \multirow[t]{2}{*}{7} & $9.897377862129140 \mathrm{e}-01$ & 1 & 1 \\
\hline & $1.132151810515625 \mathrm{e}-04$ & & \\
\hline \multirow[t]{2}{*}{8} & $9.897377862129140 \mathrm{e}-01$ & 1 & 1 \\
\hline & $1.132151810515625 \mathrm{e}-04$ & & \\
\hline \multirow[t]{2}{*}{9} & $1.632938603652878 \mathrm{e}-04$ & 2 & 1 \\
\hline & $9.770642951535482 \mathrm{e}-01$ & & \\
\hline \multirow[t]{2}{*}{10} & $1.632938603652878 \mathrm{e}-04$ & 2 & 2 \\
\hline & $9.770642951535482 \mathrm{e}-01$ & & \\
\hline \multirow[t]{2}{*}{11} & $1.632938603652878 \mathrm{e}-04$ & 2 & 2 \\
\hline & $9.770642951535482 \mathrm{e}-01$ & & \\
\hline \multirow[t]{2}{*}{12} & $1.632938603652878 \mathrm{e}-04$ & 2 & 2 \\
\hline & $9.770642951535482 \mathrm{e}-01$ & & \\
\hline \multirow[t]{2}{*}{13} & $1.632938603652878 \mathrm{e}-04$ & 2 & 2 \\
\hline & $9.770642951535482 \mathrm{e}-01$ & & \\
\hline
\end{tabular}

where class 1 is for healthy case and class 2 is for the cracked case.

These early defect detection based on this signal data was the subject in many researches $[32,33]$. Parey et al [32] showed that the defect can be detected on the 10th day in place of the 11th day, with kurtosis only, by using the Empirical Mode Decomposition and kurtosis values of each IMF are calculated. Elbadoui [33] found that the cepstral peak of the wheel, which develops the fault (A1), increases at the expense of 
the other. The sum of the first peak is always close to 0.5 , which shows that the processed signals are not very noisy. The evolution of the indicator makes it clear that from the 8th day the pinion develops a fault. This result is consistent with the observation made on the expertise of the gearbox system, which is the occurrence of chipping on the top of the tooth $15 / 16$ on the 8 th day. In other works, it was possible to detect the occurrence of a very marked fault before the 10th day [31, 33, 34]. Merzoug et al [31] indicated that it is not possible to early detection of the occurrence of a fault with the times signal. They used the decomposition of the experimental signal approximations and evolution of kurtosis, which shows the early fault detection on the 4th day after the approximation 4.This result approves our choice of the DWT for features extraction in order to test the power of the proposed method in the field of the early fault detection in gears and gearbox with experimental signals. After decomposing signal into approximations and details by the DWT, the PCA of approximations is calculated. The MLP is trained by 5 signals and tested by 12 signals with the obtained value for the MSE is equal to 5.97.10-7 with 29 iterations. It is assumed that defects appear only on the 10th day as represented in Table 2.The rate of correct classification is $83.33 \%$, signals of the 4th and 9th day are classified as defected. Indeed in the references $[29,31,32]$ the presence of defect is before the $10^{\text {th }}$ day.

\section{CONCLUSIONS}

In this paper the ANNs incorporating DWT with PCA based gear fault detection are developed. The simulated signal data are collected by simulation of a gearbox system. The features extraction is made by the DWT with PCA. The proposed method provides a decision aid in the field of preventive maintenance and able to detect gear defects with a good rate of classification. Two types of signal are tested; simulated and experimental, which show that this classification is not restricted to simulated data. It still uses a big data with different types of defect which is the area of our features research work.

\section{ACKNOWLEDGEMENTS}

The authors would like to thank Sultan Moulay Slimane University, Industrial Engineering and Sustainable development Laboratories.

\section{REFERENCES}

[1] Li B, Zhang P-1, Wang Z-j, Mi S-s, Zhang Y-t. Gear fault detection using multiscale morphological filters. Measurement. 2011;44:2078-89.

[2] Kidar T. Diagnostic des défauts de fissures d'engrenages par l'analyse cyclostationnaire école de technologie supérieure - université du québec en cotutelle avec l'université jean monnet de saint-etienne, France; 2015.

[3] Li H, Zheng H, Tang L. Gear fault detection based on Teager-Huang transform. International Journal of Rotating Machinery. 2010;2010:9.

[4] Yunoh MFM, Abdullah S, Saad MHM, Nopiah ZM, Nuawi MZ. Fatigue feature extraction analysis based on a K-means clustering approach. Journal of Mechanical Engineering and Sciences. 2015;8:1275-82.

[5] Hafizi ZM, Epaarachchi J, Lau KT. An investigation of acoustic emission signal attenuation for monitoring of progressive failure in fiberglass reinforced composite laminates. International Journal of Automotive and Mechanical 
Engineering. 2013;8:1442-56.

[6] Srihari PV, Govindarajulu K, Ramachandra K. A method to improve reliability of gearbox fault detection with artificial neural networks. International Journal of Automotive and Mechanical Engineering. 2010;2:221-30.

[7] Samanta B. Gear fault detection using artificial neural networks and support vector machines with genetic algorithms. Mechanical Systems and Signal Processing. 2004;18:625-44.

[8] Wuxing L, Tse PW, Guicai Z, Tielin S. Classification of gear faults using cumulants and the radial basis function network. Mechanical Systems and Signal Processing 2004;18:381-9.

[9] Lei Y, Zuo MJ. Gear crack level identification based on weighted Knearest neighbor classification algorithm. Mechanical Systems and Signal Processing. 2009;23:1535-47.

[10] Saravanan N, Cholairajan S, Ramachandran KI. Ibration-based fault diagnosis of spur bevel gear box using fuzzy technique. Expert Systems with Applications. 2009;36:3119-35.

[11] Chen Z, Li C, Sanchez R-V. Gearbox fault identification and classification with convolutional neural networks. Shock and Vibration. 2015;2015:10.

[12] Tian X. Dynamic Simulation for System Response of Gearbox Including Localized Gear faults: University of Alberta 2005.

[13] Mohammed OD, Rantatalo M, Aidanpää J-O, Kumar U. Vibration signal analysis for gear fault diagnosis with various crack progression scenarios. Mechanical Systems and Signal Processing 2013;41:176-95.

[14] Chaari F, Baccar W, Abbes MS, Haddar M. Effect of spalling or tooth breakage on gearmesh stiffness and dynamic response of a one-stage spur gear transmission. European Journal of Mechanics A/Solids. 2008;27:691-705.

[15] Chaari F, Fakhfakh T, Haddar M. Analytical modelling of spur gear tooth crack and influence on gearmesh stiffness. European Journal of Mechanics A/Solids. 2009;28:461-8.

[16] Wu S, Zuo MJ, Parey A. Simulation of spur gear dynamics and est-imation of fault growth. Journal of Sound and Vibration. 2008;317:608-24.

[17] Mohammed OD, Rantatalo M, Aidanpää J-O. Improving mesh stiffness calculation of cracked gears for the purpose of vibration-based fault analysis. Engineering Failure Analysis. 2013;34:235-51.

[18] Bartelmus W. Mathematical modelling and computer simulations as an aid to gearbox diagnostics. Mechanical Systems and Signal Processing. 2001;15:85571.

[19] Ozguven HN, Houser DR. Mathematical models used in gear dynamics-a review. Journal of sound and vibration. 1988;121:383-411.

[20] Yang DCH, Lin JY. Hertzian damping, tooth friction and bending elasticity in gear impact dynamics. Journal of Mechanisms,Transmissions and Automationin Design 1987;109:189-96.

[21] Sainsot P, Velex P. Contribution of gear body to tooth deflections - a new bidimensional analytical formula. Journal of Mechanical Design. 2004;126:74852.

[22] Chui CK. An Introduction to Wavelets: Academic press; 1992.

[23] Meyer Y, Roques S. Progress in Wavelet Analysis and Applications. 1993. p. 785.

[24] Mallat SG. A theory for multiresolution signal decomposition: the wavelet representation. IEEE Transactions on Pattern Analysis and Machine Intelligence. 
1989;11:674 - 93.

[25] Shlens J. A tutorial on principal component analysis derivation, discussion and singular value decomposition. version 1 ed2003.

[26] Briand M. Etudes d'algorithmes d'extraction des informations de spatialisation sonore : application aux formats multicanaux: l'institut national polytechnique de Grenoble; 2007.

[27] Rosenblatt F. Principles of neurodynamics; perceptrons and the theory of brain mechanisms. Cornell Aeronautical Lab Inc Buffalo; 1962.

[28] Belaidi I, Tahmi R, Mohammedi K. Configuration optimale d'un réseau de neurons adapté à la surveillance en ligne de l'usure des outils de tournage. 18 ème Congrès Français de Mécanique. France; 2007.

[29] Kohonen T, Mäkisara K, SImula O, Kangas J. Artificial neural networks. Proceedings of the 1991 International Conference on Artificial Neural Networks (ICANN-91) Espoo, Finland; 1991.

[30] Drouiche K, Sidahmed M, Grenier Y. Détection de défauts d'engrenages par analyse vibratoire. Journal de traitement de signal. 1999;8:331-43.

[31] Merzoug M, Ait-Sghir K, Miloudi A, Dron JP, Bolaers F. Early detection of gear failure by vibration analysis. Multiphysics Modelling and Simulation for Systems Design and Monitoring MMSSD. Tunisia: Springer; 2014. p. 69-79.

[32] Parey A, Badaoui ME, Guillet F, Tandon N. Dynamic modelling of spur gear pair and application of empirical mode decomposition-based statistical analysis for early detection of localized tooth defect. Journal of sound and vibration. 2006;294:547-61.

[33] El Badaoui M. Contribution au Diagnostic Vibratoire des Réducteurs Complexes à Engrenages par l'Analyse Cepstrale: University Jean Monnet Saint Etienne; 1999.

[34] Haloui N, D.Chikouche, .Benidir M. Diagnosis of gear systems by spectral analysis of vibration signals. I International Journal of Computer Science and Network Security IJCSNS. 2007;7:285-93. 